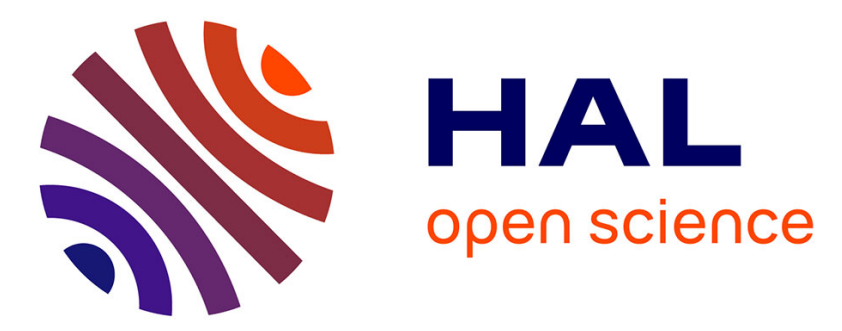

\title{
PROPAGATION EFFECTS AND OPTICAL NONLINEARITIES OF EXCITONS IN MULTIPLE QUANTUM-WELLS
}

\author{
J. Levenson, R. Raj, I. Abram, G. Dolique, F. Alexandre
}

\section{- To cite this version:}

J. Levenson, R. Raj, I. Abram, G. Dolique, F. Alexandre. PROPAGATION EFFECTS AND OPTICAL NONLINEARITIES OF EXCITONS IN MULTIPLE QUANTUM-WELLS. Journal de Physique Colloques, 1987, 48 (C5), pp.C5-541-C5-544. 10.1051/jphyscol:19875116 . jpa-00226699

\section{HAL Id: jpa-00226699 https://hal.science/jpa-00226699}

Submitted on 1 Jan 1987

HAL is a multi-disciplinary open access archive for the deposit and dissemination of scientific research documents, whether they are published or not. The documents may come from teaching and research institutions in France or abroad, or from public or private research centers.
L'archive ouverte pluridisciplinaire HAL, est destinée au dépôt et à la diffusion de documents scientifiques de niveau recherche, publiés ou non, émanant des établissements d'enseignement et de recherche français ou étrangers, des laboratoires publics ou privés. 


\title{
PROPAGATION EFFECTS AND OPTICAL NONLINEARITIES OF EXCITONS IN MULTIPLE QUANTUM-WELLS
}

\author{
J.A. LEVENSON, R.K. RAJ, I. ABRAM, G. DOLIQUE, F. ALEXANDRE \\ Centre National d'Etudes des Télécommunications, Laboratoire de \\ Bagneux (1), 196. Avenue Henri Ravera, F-92220 Bagneux, France
}

\begin{abstract}
RESUME : Nous avons étudié les mecanismes qui sont a l'origine des nonlinearites optiques excitoniques dans les Multipuits Quantiques GaAs/ GaAlAs. L'analyse des spectres obtenus revele, outre les nonlinéarités attendues, des effets propagatifs fortement dépendent de la température. Ces résultats mettent en avant le rôle de la propagation de la lumiere a travers un milieu non-linéaire.
\end{abstract}

\begin{abstract}
We have investigated the mechanisms that give rise to the optical nonlinear response associated with excitons in 2D GaAs/GaAlAs Multiple Quantum-We11 (MQW) structures. The analysis of the spectra has revealed in addition to the expected sources of excitonic optical nonlinearity, temperature dependent propagation effects. These experiments bring to the fore the role of light propagation through a nonlinear medium.
\end{abstract}

\section{INTRODUCTION}

The large room-temperature optical nonlinearities of excitons in GaAs/GaAlAs Multiple-Quantum Wells (MQW) have elicited a lot of interest in recent years. However, the detailed interpretation of nonlinear optical experiments on MQW is still subject to controversy, as the macroscopic manifestations of these nonlinearities (refractive or absorptive changes) as well as their incidence on light propagation through the sample, are still not well understood.

Room-temperature nonlinear optical experiments in a 65-period thick MQW have indicated that the contribution of the heavy exciton in degenerate four wave mixing (DFWM) is much larger than that of the light exciton, while in the nonlinear transmission (NLT) spectra the peaks of the two excitons were of comparable intensities ${ }^{1}$. This was attributed to the different contribution of the real and imaginary parts of the effective third-order susceptibility in the two nonlinear techniques. This conclusion, however, is at variance with experiments at liquid Helium temperatures $2 \mathrm{~J}$ where both DFWM and NLT give a large contribution for the heavy exciton. In addition, the difference between the room-temperature and lowtemperature results has not received an adequate explanation.

In this communication we show that propagation effects can account for the main features of all these nonlinear spectra.

(1) Laboratoire associé aU CNRS (UA 250) 


\section{EXPERIMENTAL}

Our samples are MBE-grown GaAs/Ga ${ }^{A l}$ As MQW, with 120 Awide wells and $80 \AA$ barriers. The MQR reglon is sandwiched between two 2-micron thick layers of $\mathrm{Ga}, \mathrm{Al}^{\mathrm{Al}} \mathrm{B}^{\mathrm{As}}$. Two types of samples were used, having thicknesses of $30^{\circ}$ and $80^{3}$ periods respectively. A $2 \mathrm{~mm}^{2}$ hole was etched chemically in the GaAs substrate to allow optical transmission experiments in the NQW.

The light source is a parametric generator producing 10-psec long infrared pulses of peak intensity $100 \mathrm{KW} / \mathrm{cm}^{2}$, having a spectrai width of $1 \mathrm{meV}(0.5 \mathrm{~nm}$ at $800 \mathrm{~nm})$. It consists of several $\mathrm{LiIO}_{3}$ crystals (total effective length $10 \mathrm{~cm}$ ) pumped at $532 \mathrm{~nm}$ by the second harmonic of a pulsed, mode-locked YAG laser. Wavelength can be scanned by angle-tuning the $\mathrm{LiIO}_{3}$ crystals.

The output of the parametric generator is split into two beams which are recombined inside the sample. One beam (pump) is very intense so that it produces optical saturation, while the second (probe) is attenuated so as not to produce any nonlinear effects. The probe transmission through the sample is measured both in the presence and in the absence of the pump, and the two measurements are ratioed. The nonlinear spectrum thus gives the pump-induced transmission of the probe, as a function of the wavelength of the incident radiation.

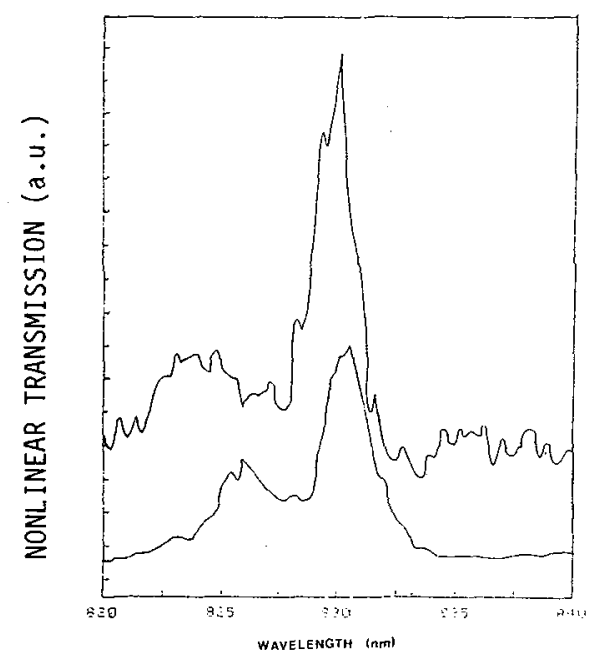

Figure 1

Nonlinear Transmission spectra at $200 \mathrm{~K}$.

(a) 60 - period sample

(b) 30- period sample

Heavy exciton is at $831 \mathrm{~nm}$

Light exciton is at $825 \mathrm{~nm}$

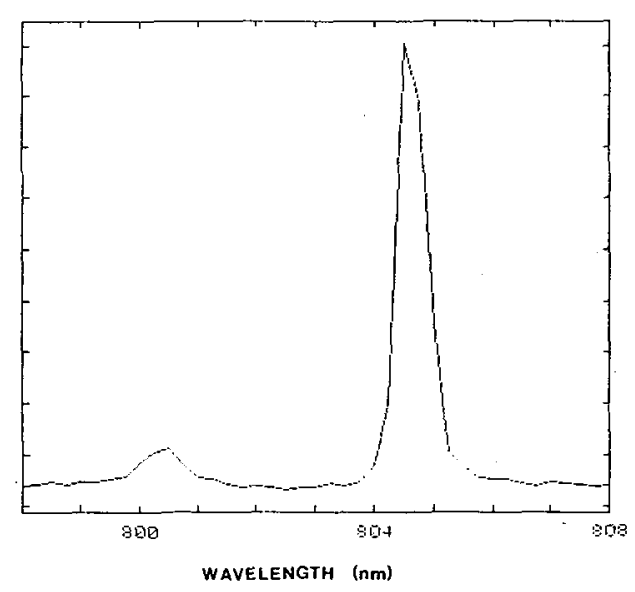

Figure 2

Nonlinear Transmission Spectrum at $10 \mathrm{~K}$.

60- period sample

Heavy exciton is at $804.5 \mathrm{~nm}$ Light exciton is at $800.5 \mathrm{~nm}$

Figure 1 reproduces the NLT spectra of the $60-$ and $30-$ period samples at $200 \mathrm{~K}$. The room temperature spectra diplay similar charecteristics but with lower $\mathrm{s} / \mathrm{N}$ ratio. In the 60 -period sample the heavy and light hole exciton signals have comparable intensities while in the 30 period sample the heavy exciton is dominant. At 10 $\mathrm{K}$, however, (Figure 2) the heavy exciton dominates for both the 60- 
and 30-period samples. DFWM spectra of the 60-period sample were also obtained, but are not displayed here; they resemble those of Figure 2 , in that they show a very strong heavy exciton.

The dominant heavy exciton contribution obtained with our samples by the DFWM and the low-temperature NLT methods is similar to the published NIT and DFWM spectralI, 2 . In the 60-period sample at room temperature, the results are once again similar to published spectra in that the heavy and light excitons have comparable strengths (with minor differences in the lineshapes probably due to different pumping conditions: our pump intensities are 100 times that in Ref. 1). On the other hand, the 30-period room temperature spectrum, displays a completely different behaviour: the heavy exciton is very strong, comparable thus to the. DFWM or the lowtemperature NLT results.

This last feature points to propagation effects in the nonlinear spectra, since the only physical difference between the two types of samples is that light travels twice the distance in the thick samples. These effects are discussed in the next section.

\section{DISCUSSION}

The room-temperature absofption coefficient at the peak of the heavy exciton in these MQW's
This implies that linear propagation of a beam entails attenuation by a factor of 4 or 5 for a $60-$ (or 65-) period MoW. If the overall bleaching is weak, saturation is proportional to the local intensity, and this latter quantity differs by a factor of 5 between the two ends of the sample. For the light exciton, the absorption coefficient is slightly lower, so that bleaching is probably a little more uniform. In a pump-and-probe experiment, the probe beam averages the information of all the layers it traverses. The NLT spectrum is thus averaged over the whole thickness of the sample, giving practically the same average NLT for the heavy and light excitons in an optically thick sample. The thin-sample result, on the other hand, gives the NLT spectrum with higher fidelity since these propagation effects are less important.

In DFWM the diffraction efficiency of the transient grating is proportional to the square of the local incident intensity. The DFWM signal thus originates essentially at the upstream end of the sample, since the first few layers contribute 25 times more than the last few layers. Thus, as observed experimentally, the DFWM result always resembles the thin-sample spectrum.

At low temperatures, an additional effect comes into play. The homogeneous spectral width of the excitons, becomes of the order of .1 mev [3], much smaller than their inhomogeneous width (of the order of $3 \mathrm{mev}$ ). This latter quantity represents the statistical distribution of the (local) exciton resonance frequency, which in turn $\left[\frac{i}{4} s\right.$ due to local variations of the widths of the quantum wells ${ }^{[4]}$. These statistical variations are distributed spatially in the sample in all three dimensions, so that when propagating along the MQW axis in a small area of the sample, many different excitonic resonance frequencies are encountered. clearly, when the ratio of the homogeneous to the inhomogeneous widths of the excitons decreases, the probability of encountering excitons with overlapping spectra, also decreases. Thus, in the course of propagation of a light beam, in a small area of the sample, very few layers can participate in the absorption (saturation process) of a particular spectral component of the beam, when the homogeneous wiath of the 
excitons is much smaller than their statistical distribution. The low-temperature NLT spectrum thus corresponds to a thin-sample spectrum, with a strong heavy exciton contribution.

Clearly, these propagation effects can explain the overall appearance of the nonlinear spectra. Other physical processes, however, may also come into play. For example, the relative magnitudes of the heavy and light exciton nopljnearities are certainly influenced by refractive effects in DFWM ll, or by thermal occupation effects at low temperatures. However, in thick samples, the exact relationship of the two peaks, is masked by propagative effects. A more quantitative treatment of propagative effects will be given elsewhere.

\section{CONCLUSION}

Our experiments have brought forth the effects of propagation in the nonlinear spectroscopy of MOW, which result from the intertwining of the saturation of the excitonic resonances with the depletion of the pump upon propagation. Consideration of such propagative effects is necessary for the intrepretation of nonlinear optical spectra, as well as for modelling MQW-based nonlinear optical devices.

\section{REFERENCES}

[1] D.S. Chemla, D.A.B. Miller, P.W. Smith, A.C. Gossard and W. wiegmann, IEEE J. Quantum Electron., QE-20, 265 (1984)

[2] J. Hegarty, M.D. Sturge, A.C. Gossard and W. Wiegmann, Appl. Phys. Lett. 40, 132 (1982)

[3] J. Hegarty, M.D. Sturge, C. Weisbuch, A.C. Gossard and W. Wiegmann, Phys. Rev. Lett. 49,930 (1982)

[4] G. Bastard, C. Delalande, M.H. Meynardier, P.M. Frijlink and M. Voos, Phys. Rev. B 29,7042 (1984); C. Weisbuch, R. Dingle, A.C. Gossard and W. Wiegmann, Solid state Commun., 38, 709 (1981) 